\title{
Silva Freire: Um garimpeiro de palavras
}

\author{
Isaac Newton Almeida Ramos ${ }^{1}$
}

RESUMO: O Concretismo revelou bons nomes para a literatura brasileira. Um deles, Silva Freire, responsável pela revista Movimento, da UNE, no final da década de 50. Com algumas publicações em edições limitadas nas décadas de 60 e 70, Águas de visitação, seu primeiro livro, saiu somente em 1979. Deste livro, o poema "Garimpo da infinitude" é uma boa amostra de sua estética literária. Participou do movimento Poema Processo.

ABSTRACT: Concretism revealed good names to Brazilian literature. One of them was Silva Freire, responsible for the magazine Movimento, by UNE in at the end of the 1950s. This magazine had some issues with limited editions during the 1960s and the 1970s. Águas de visitação, his first work, was published only in 1979. From this book, the poem Garimpo da infinitude is a good sample of his literary aesthetic. He participated in the movement process-poem.

PALAVRAS-CHAVE: Silva Freire; vanguardas poéticas; concretismo; poemaprocesso.

KEYWORDS: Silva Freire; poetic vanguards; concretism; process-poem.

\section{Um pouco da sua biografia}

Benedito (por promessa de vida ao Santo Pretinho), Sant'Ana (homenagem à Santa de devoção) e da Silva (sobrenome da mãe) Freire (sobrenome do pai), nasceu em 20 de setembro de 1928, em Mimoso, terra de Cândido Rondon, hoje Santo Antonio de Leverger (MT). Mudouse cedo para Cuiabá, cidade em que foi registrado. Fundou, em Mato Grosso, juntamente com Wlademir Dias Pino, os jornais Arauto da Juvenília e O Saci (1949) e Sarã (1951). Neste apresentou o manifesto do movimento "intensivista", que se propunha ao simbolismo duplo, defendendo que, além da imagem, há outros significados poéticos. No

\footnotetext{
${ }^{1}$ Doutorando em Estudos Comparados de Literaturas de Língua Portuguesa, FFLCHUSP. Pesquisa: Poéticas visuais comparatistas: Brasil e Portugal.

E-mail: isaac.3@hotmail.com. e isaacramos3@terra.com.br. Bolsista CAPES.
} 
Rio de Janeiro, os dois editaram o jornal Japa, em 1953, com a finalidade de publicar jovens autores. Em 1956, foi presidente do Teatro Universitário Brasileiro da UNE (1956/59) e Secretário de Cultura da mesma entidade. Freire foi responsável, novamente com Dias Pino, pela revista Movimento, no período supracitado. Segundo depoimento dele, essa publicação - que foi um marco durante quase duas décadas - teria sido premiada em Ibadan (Nigéria) e Oxford (Inglaterra), em duas conferências internacionais de imprensa universitária. Ainda, em 1956, patrocinou a "Noite de Arte Concreta", com debates e poemas dos irmãos Augusto e Haroldo de Campos, Décio Pignatari, Wlademir Dias Pino, Ronaldo Azeredo e Ferreira Gullar.

Depois de concluir o curso de Direito, voltou para Cuiabá e como intelectual batalhou pela recriação da Faculdade de Direito de Cuiabá. Posteriormente, exerceu a docência nessa área, por mais de uma década, na Universidade Federal de Mato Grosso. Notícias sobre a sua poesia foram publicadas em jornais do Rio, São Paulo, Brasília, Goiânia e Paraíba. Em 1967, Silva Freire participou do movimento "Poema Processo", uma das dissidências do Concretismo, ao lado do inseparável amigo Dias Pino, mentor intelectual do grupo. Em 1971, teve participação no livro Processo: Linguagem e Comunicação, publicado pela editora Vozes (Petrópolis), de grande importância no contexto do movimento poema-processo. A abordagem desse livro será feita no próximo item. Durante os anos 60 e 70, teve cerca de doze publicações denominadas Caderno de Cultura. Os poemas contidos nesses cadernos, em geral, vinham dispostos em blocos poemáticos, normalmente com um tema comum, partindo do micro universo cultural cuiabano para o macro universo do leitor.

O seu primeiro livro, Águas de Visitação (1979), veio coroar um trabalho de quase três décadas. Alguns dos poemas já haviam sido publicados nos referidos cadernos de cultura. Águas de Visitação é constituído de onze poemas, todos erguidos em blocos poemáticos. Permeia a obra uma poesia lírica, social, concreta e caleidoscopicamente metafórica. Uma rápida observação dos títulos dá 
a idéia de sua temática: "garimpo da infinitude"; "os oleiros"; "cerrado/raízes”; "carvoeiro/vegetal”; seringal/seringueiro”; "canavial”; "as redes"; "os cavalos"; "giro do couro cru"; "os pássaros" e "campus de universidade”. Esta obra teve quatro edições, a última delas, póstuma. Em 1989, publicou Barroco Branco e no ano em que faleceu, 2001, saiu a Trilogia Cuiabana - da qual, apesar do título, foram publicados apenas dois livros.

Silva Freire também se destacou como dirigente cultural no seu Estado de origem. Além da experiência vivida no Rio de Janeiro, nos tempos da UNE, na década de 70, fez parte de um triunvirato com Dias Pino e o intelectual Célio da Cunha, com o intuito de promover o carnaval cuiabano. Em 1976, como coordenador de arte do município de Cuiabá, promoveu o evento “Cuiabá 200 anos de carnaval”. Deste evento resultou a publicação de uma revista, com o mesmo título, e encartes em jornais da época. Na década de 60, o poeta e comunicador visual Dias Pino viveu experiência semelhante no Rio de Janeiro. Ele foi convidado, por mais de um ano, para ser o responsável pela organização visual externa do carnaval carioca. Brilhou na metrópole carioca e somente uma década mais tarde, a capital mato-grossense foi contemplada com o trabalho gráfico desse artista, tendo o reforço do velho parceiro, Silva Freire, e o acréscimo do intelectual Célio da Cunha. Esses trabalhos carnavalescos ocorreram em 1976 e 1977. No primeiro ano Freire publicou, no encarte/programa, o poema “cerrado/coração ancestral”. Passar a vista por dois blocos do referido texto dá uma idéia da literariedade desse vanguardista. Nesse trecho, o cerrado não é mais apenas o que se vê, traz nele as marcas incisivas da história: 
(...)

_ cerrado:

tecido telúrico

/processo/

o ingresso na história

ou

regresso atávico

à origem da raça/ cuiabania

(...)

- e raça se pereniza:

no caldo quente do tempo

no curvo eco do abraço

na seiva-sangue do jatobá

é paratudo medicinal

é suco-saúde e velaime

êta/ amargo de fedegoso

na forte essência do guaraná

(FREIRE, Silva. "Separata da Revista/Documento" In: Cuiabá/200 anos de carnaval. Prefeitura Municipal de Cuiabá: 1976)

A partir da citação acima, é possível observar que Freire mostra a cultura cuiabana de forma metonimizada. $\mathrm{O}$ aspecto formal desse poema faz lembrar a primeira geração modernista, com a quase ausência de pontuação e letras maiúsculas. Estruturalmente, a ocupação do espaço na folha (a sintaxe), com os versos recuados em vários momentos, lembra a imagem do próprio cerrado, que é uma vegetação típica da região Centro-Oeste e, igualmente, remete ao concretismo. Mais do que um cerrado, é um coração ancestral que se anuncia pelos (des)vãos das batidas ritmadas de um povo que luta pelo reconhecimento de sua cultura. Esse tecido telúrico do qual é formado o cerrado (re)cria um universo fantasmático cuiabano. Na verdade, os princípios do chamado movimento intensivista já propugnava esse duplo sentido de cidadania e poética anunciada ou, em outras palavras, um duplo signo. Esse espírito encarnado de molecagem poética aparecerá de forma mais consistente e lúdica em poemas da Trilogia Cuiabana. Nesse livro há um diálogo quase que intermitente com a tradição do cuiabano, com o seu falar, como um manifesto poético que não deseja calar: “- já ta de férias/cerinha?/ - sim senhor/pai/ - então 
acorda cedinho/prá ficar/ de não fazer mais nada...” (FREIRE, 1991, p.205).

No ano de 1977, Freire, Dias Pino e Célio Cunha divulgam o "Manifesto Mosaico Cuiabano”, que mais parece um dos manifestos das vanguardas literárias, em virtude de proposições estéticas à cultura cuiabana: "Somos um POVO cuja sensibilidade soube aclimatar o quente arabesco do tapete persa no ritmo alegre e dançarino do MOSAICO geometrizante!"2 (FREIRE; PINO \& CUNHA, 1977, p.3) A quase poesia matemática, que procurará abolir as palavras, é uma das tendências do poema-processo que se faz anunciar em alguns trechos: "Nossa intimidade é geométrica, ilustrada pelo ornato denso dos florais agrícolas, das linhas retas que alimentam a estrutura do mosaico, (...) à semelhança da linha que se estica pelo peixe fisgado na memória/paladar do pescador nativo". Ou mesmo para mostrar a influência de uma cidade que nasceu por causa do garimpo. Mais do que nunca, há um intenso (re)mostrar dos primórdios dessa gente, da madurez dos mais de duzentos anos de história, das ruínas arquitetadas pelas riquezas que atravessaram as bateias em dias ensolarados. Nada escapa à lente destes poetas. Nos becos quentes e ruas atravessadas por geômetras da poesia, o povo não mais se escandaliza pelo rico passado perdido que Mato Grosso viveu. O que, aparentemente, parece importar é o desfrute do folião, carregado de um sentimento de cidadania, que não pode se perder jamais.

Voltando ao "manifesto", dessa forma se dirigem ao folião:

Como toda cidade garimpeira, nascemos rente ao topográfico, rasgando a geografia em veias. Nossas ruas não são tortas. São anguladas como o diamante, como o escudo que defende o índio, como o bordado tropeiro na rede: - o diamante, no carrinho da lapidação, é que ganha intimidade humana! (Op. cit., 1977, p.3).

\footnotetext{
2 FREIRE, Silva; PINO, Wlademir Dias \& CUNHA, Célio da. "Carnaval 77 - Manifesto Mosaico Cuiabano". In: Diário de Mato Grosso. Cuiabá, MT. Suplemento $\mathrm{n}^{\circ} 3$, fev. 1997.
} 
E assim, Silva Freire e seus parceiros vão apresentando o cerrado de diamantes feitos de palavras, que lapidam à medida que o leitor vai decifrando os (des)códigos poéticos. É a palavra lapidada na ranhura do poema, que vai se encorpando, que vai intermediando à folia do manifesto. É como a bateia do garimpo, que seleciona as pedras certas e joga fora o brilho que não é de valor.

\section{Acerca do Concretismo e do Poema-Processo}

A Literatura Brasileira, durante o Modernismo, experimentou diversas experiências de poéticas de vanguarda, seja na Semana da Arte Moderna de 22, seja em meados do século XX com o Concretismo, Neoconcretismo, Poema Práxis, até chegar ao Poema-Processo. Em livros didáticos e em manuais, como História Concisa da Literatura Brasileira, de Alfredo Bosi, o Concretismo tem o seu espaço reservado. Já os movimentos provenientes das diversas intersecções de vozes, como é o caso do poema-processo, poderiam ter recebido uma melhor atenção da crítica. Por ocasião das comemorações dos 50 anos do Concretismo, em 2006, essa lacuna foi relativamente preenchida através de uma série de textos publicados a respeito do assunto, seja em livros ou revistas especializadas. No caso das revistas, o destaque fica para a conceituada $O$ eixo e a roda - Dossiê 50 anos do Concretismo, do programa de Estudos Literários da UFMG. O problema é que uma parcela muito pequena do que é produzido na e para a academia chega a ser publicada em livros. Um exemplo dessas gratas exceções é o livro Impressões de viagem: cpc, vanguarda e desbunde: 1960/703 de Heloisa Buarque de Hollanda. Na internet, encontra-se um número considerável de blogs de admiradores desses movimentos.

O Movimento da Poesia Concreta surgiu, no Brasil, na segunda metade da década de 50. No exterior, ele se expandiu nas décadas de 60

\footnotetext{
3 Trata-se de um texto adaptado da tese de doutoramento em Literatura Brasileira, defendida na Faculdade de Letras da UFRJ, sob a orientação do Prof. Afrânio, 1978. A $1^{a}$ edição é de 1980, pela Brasiliense.
} 
e 70, fruto, principalmente, do empenho e dedicação dos membros do grupo "noigrandes". Como poetas, Haroldo de Campos e Augusto de Campos tiveram maior visibilidade. O resultado disso foi a produção de um maior números de estudos críticos sobre as suas obras. No que tange a autoria dos manifestos, a tarefa foi dividida entre os irmãos Campos e Décio Pignatari. O movimento em si se caracterizou por um radicalismo morfológico textual, simultaneidade dos signos verbais e não-verbais, visualidade visual e objetiva, de forma que a palavra fez-se objeto, o texto, fez-se matéria e instalou-se a sintaxe combinatória. Além disso, a relação significante / significado estabelece em uma semântica outra, posto que na poesia concreta ocorre a espacialização dos signos verbais.

No concretismo, provavelmente por ser vanguarda, houve a necessidade de um manifesto: "Plano Piloto para a Poesia Concreta" (1958), assinado pelos fundadores do Grupo Noigrandes, ou seja, os irmãos Campos e Pignatari. Este texto foi posteriormente publicado no livro Teoria da Poesia Concreta: textos críticos e manifestos 1950-1960, que ganhou nova edição em 2006. No poema-processo, o manifesto foi publicado no livro Processo: linguagem e comunicação. Como o segundo derivou do primeiro, as bases teóricas possuem algumas leituras em comum. Nesse sentido não é de se estranhar a recuperação da Poesia Barroca e da tradição do visualismo mediterrâneo, fazendo intertextualidade com a Poesia Concreta. E para completar a prática dos concretistas, deve-se ter em mente Mallarmé (página em branco), Fenollosa (ideogramas chineses), Ezra Pound (método ideogramático) e James Joyce (isomorfismo verbivocovisual) e estará formada a base para o concretismo.

A partir desta base, tem-se o advento do chamado PoemaProcesso, assim registrado na primeira página do livro Processo: linguagem e comunicação.

Os poetas do movimento do Poema-Processo (livres do sofisticado do heroísmo) têm a consciência das dificuldades de ser vanguarda e mais do que isso, sabem que ao dissociar a Poesia 
(estrutura) do Poema (processo), separaram, definitivamente, o que é língua de linguagem dentro da literatura. (PINO, 1973, s/n)

Essa publicação, a exemplo da Teoria da Poesia Concreta do grupo Noigrandes, reuniu conceituações sobre o movimento fundado por Dias Pino, trazendo seus depoimentos e trabalhos poéticos dos principais representantes do Poema-Processo, dentre eles Álvaro de Sá, Silva Freire, Moacy Cirne, Neide Sá e outros. Esses textos fizeram parte da "4⿳亠丷厂 Exposição Nacional de poema/processo", em abril de 1968, no Museu de Arte Moderna da Bahia. Essa obra abre uma concessão, na visão dos adeptos da poesia visual, sob a forma de livro, com o intuito de divulgar entre os leitores o material dessa exposição.

Segundo Hilda Dutra Magalhães, Silva Freire é um "autor experimental, sua arte desafia o bom tom e o conservadorismo da literatura clássica" (2001, p. 162). Rubens de Mendonça, historiador, em 1970, publicou a primeira edição da História da Literatura MatoGrossense ${ }^{4}$. Esse livro foi o primeiro a apresentar, de forma significativa, um mapeamento de autores que produziram nesse Estado. De forma bem humorada, ao falar sobre um poema escrito por Silva Freire, dedicado ao Marechal Rondon, assim se expressou: "o verso não entendi, mas foi muito elogiado por Gervásio Leite e João Antonio Neto" (2005, p.196). Mendonça reproduz ainda as considerações do amigo Gervásio Leite sobre a poética de Silva Freire: "não é atividade lúdica, é experiência séria, pesquisa original, reinterpretaçao da palavra ou a sua adequação ao mundo em que vivemos". (MENDONÇA, op. cit. p. 197)

Ao falar sobre a Trilogia cuiabana, de Silva Freire, Gomes afirma que bem poderia se chamar Anatomia cuiabana, dado o visceral compromisso com a cuiabania: "Silva Freire, ao incorporar o patrimônio popular à tradição vanguardista do Concretismo, une o popular ao

4 Em 2005, esse livro teve uma segunda edição especial, publicado pela Unemat Editora, contendo ao final uma pequena fortuna crítica. Essa reedição é fruto de um projeto de pesquisa intitulado "Preservação e difusão da Literatura Mato-Grossense do início do século XX", na época coordenado por Genivaldo Rodrigues Sobrinho (doutorando da USP) e a participação da atual coordenadora Drª Walnice Vilalva. 
erudito, dialogando com os textos históricos, jornalísticos, jurídicos e outros, na confabulação do texto novo" (2001, p.171).

\section{Um garimpeiro de palavras}

Após a necessária e breve apresentação de Silva Freire, e a abordagem de alguns aspectos acerca do concretismo e do poemaprocesso, passemos a algumas considerações do poema "garimpo da infinitude". Ele é o primeiro poema do livro Águas de visitação e simboliza, de maneira inusitada, um dos tipos humanos do homem do interior retratados nesse livro. Este é composto por 44 blocos poemáticos. A disposição estrutural do poema em blocos, não lineares ou homogêneos, é uma das características formais do autor. Em diversos momentos ele explora a visualidade, a ponto de ser táctil ou mesmo semovente. Para obedecer às dimensões de um artigo foram selecionados apenas dez blocos.

Mesmo que o leitor não tenha muita intimidade com expressões próprias do garimpo, é possivel vislumbrar imageticamente a plasticidade do poema. Além disso, o ritmo, em diversos momentos, sinestésico, contribui com uma sonoridade impecável e ajuda a construir uma lírica social, que se apresenta aos olhos do leitor. Procura-se mostrar não apenas a zona do garimpo, o homem sulcado pela ambição de ficar rico rapidamente, os rituais seguidos, os ensinamentos da profissão, mas, sobretudo, a alma do garimpeiro, que tem como porta-voz um poeta que garimpa as palavras antes de lançálas no papel em branco. 


\section{garimpo da infinitude}

- o garimpo

vaza

eco da sorte

no pião da bateia

$$
\begin{array}{r}
\text { - o garimpo é hermético } \\
\text { estranhamente aberto } \\
\text { ao receber o rito } \\
\text { hirto } \\
\text { mito } \\
\text { e o místico }
\end{array}
$$

- o garimpeiro

crava

na lavra pálpebra/forma que arredonda o

chibiu

- o garimpeiro codifica o sonho

- o garimpeiro decodifica a minerador

leitura da mancha

\section{(...)}

o garimpeiro talha

moe

remoe

moenda

remorrendo

na brita do sol

no brilho da vida

(...)

no budum do lençol

- a barriga ruge

geme de gente

na boca da sede

na sede do engano

na seda da gema

(...)

- na eleição profissional do garimpo

o homem

oficia a rejeição

que o liberta do patrão 
(...)

- no dia do achado

um conto-de-réis

é chama que acende cigarro

(...)

- o tempo passa em pratos

os prantos

feitos

de fatos

atos

faca/

diamante de enrola

(...)

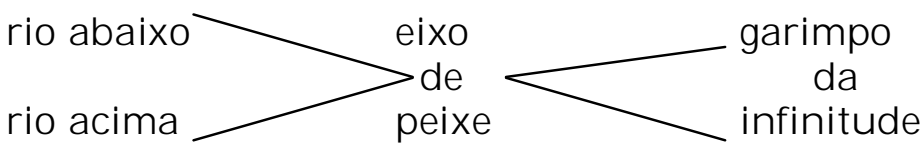

O título "garimpo da infinitude" remete automaticamente a uma sucessão de tentativas que não têm fim. Parece ser simbólico o destino do garimpeiro. Ou ele se enriquece de repente ou ele embrutece diante dos seus insucessos. O procedimento do fazer poético minerando as palavras vai aumentando, gradativamente, o grau de dificuldade para o leitor. Mesmo utilizando-se de um vocabulário próprio do garimpeiro, o poeta vai marchetando o seu texto com filigranas poéticas.

A ordem dos quatro primeiros blocos é a mesma do texto original, incluindo a disposição espacial. Nos dois primeiros, o garimpo está personificado. Freire começa por mostrar esse lugar poético “- o garimpo/ vaza/ eco da sorte/ no pião da bateia”. Essa imagem sinestésica do garimpo, com quase três sentidos, ver/sentir/ouvir, mistura-se a engrenagem do pião da bateia. Mesmo sabendo que bateia é uma espécie de gamela usada no garimpo, não há como não remeter esse eco da sorte às inúmeras tentativas que o garimpeiro faz para achar a sua fortuna. Essas tentativas, quase sempre infrutíferas, funcionam como uma espécie de roleta russa, que rodopia como pião na bateia, a ponto de deixar tonto quem nela joga o seu destino. Um único 
verbo (vaza) é utilizado. E ele se esvai como o "eco da sorte”, a ponto do conteúdo sair o significado. O substantivo é forte, concreto (no sentido morfológico) e serve como uma anunciação do poema. Quanto à sonoridade, sons nasais no primeiro e último versos /garimpo/e /pião/ recheiam vogais abertas /vaza/, / anteparo a /bateia/. O que fica é poesia.

O segundo bloco se abre com um paradoxo e uma metáfora, “- o garimpo é hermético/ estranhamente aberto". A expressão "hermético" tanto pode significar totalmente fechado como difícil de interpretar (no sentido de alquimia). Nas três palavras sublinhadas predominam o /e/ aberto e um /e/ nasal. O som nasal serve para propagar/preparar a palavra certa. Os mistérios dessa infinitude paradoxal levam o verbo transitivo direto /receber/ ao rito/hirto/mito/e místico, configurandose em uma gradação nominal. Essa gradação, cujos vocábulos estão no mesmo campo semântico, promove a propagação do fonema /i/ nas quatro palavras carregadas de simbologia e musicalidade vestida de dor, dos gritos insanos daqueles que não acharão a sua fortuna. Do ponto de vista lexical, continua o destaque para os nomes (substantivos), pois há apenas um verbo que indica ação (receber), a partir de uma frase nominal (“o garimpo é hermético”). Sintaticamente, o que vem depois dessa expressão são termos acessórios da oração, em que o rito, o mito e o místico se interpenetram, sem que nada passe batido.

No terceiro bloco, chega-se ao garimpeiro que "crava/ na lavra/ pálpebra/forma/ que arredonda o chibiu”. É o primeiro momento em que se visualiza a bateia, como forma/expressão/conteúdo. Um verbo forte se destaca /crava/, de forma intransitiva no advérbio /lavra/. Na semântica do verso, essa palavra evoca mais de um sentido, tanto no terreno da mineração quanto no sentido figurado de ser qualquer lugar onde se cria e/ou se produz algo. No segundo sentido, percebe-se o processo do poeta lavrar o poema em pálpebra/forma. Imageticamente a metáfora se insinua. Assim como palavra chibiu vem a ser uma pontinha de diamante, que, uma vez achada, sinaliza que o garimpeiro 
irá achar pedras maiores, da mesma forma o poeta, ao lavrar o poema, que provoca o arredondamento da poesia, acaba por encontrar o seu chibiu. O verbo /arredonda/ remete a uma das formas preferidas do poeta: a esfera, o oval, o círculo, etc.

O quarto bloco é formado, sintaticamente, por dois períodos simples. Dois verbos transitivos diretos - codifica/decodifica - mostram o rito da passagem do garimpeiro e do poeta, que dos seus pórticos vêem o achamento da pedra mais preciosa e da palavra mais exata. Garimpeiro e poeta comungam e festejam o advento da mineração e do fazer poético. Enquanto "o garimpeiro codifica o sonho minerador", o poeta enternece o leitor com o seu instrumento de trabalho e da mesma forma será preciso ter olhos para entretecer as palavras em busca de (re) significados. O poeta urde, o leitor entontece. Em um processo de (des)montagem e (des)fragmentação "o garimpeiro decodifica a leitura da mancha" (lugar onde tem diamante) e o poeta decodifica a expressão do leitor. Garimpeiro, poeta e leitor, passageiros de um mesmo destino. Todos em busca de suas independências, da mancha que não macule o sonho de achar a sua fortuna. Duas metáforas se cruzam a partir de um verbo - codifica - e do seu derivado. O sonho minerador e a leitura da mancha são duas ações que se completam, assim como o garimpeiro e o poeta se arriscam a buscar riquezas. Uma mineral. Outra no papel. Uma para mudar o rumo de sua vida. Outra para achar a metáfora mais do que perfeita. O leitor que interprete da melhor forma. Sons sem maiores sobressaltos misturam-se nesses dois períodos. A repetição sonora é o recurso utilizado, em semelhanças sonoras de aliteração ou ressonância. Os fonemas /i/, /o/ (fechado), /a/ (nasal) dão o tom de equilíbrio nos versos. A cadência rítmica contribui para aumentar a ressemantização do poema.

O próximo bloco traz de volta a marca da visualidade e a personificação do garimpo. A forma da bateia se amplia a partir do verso introdutório "o garimpo talha”. Esta expressão intransitiva é forte o suficiente para que o leitor busque os mais diversos significados, posto que serve tanto ao garimpeiro quanto ao poeta. O processo de 
penalização que o garimpo imprime ao garimpeiro é o mesmo, atenuada a dor física, que o poeta infringe a si próprio no processo de lavra do seu poema. É a primeira vez no poema que aparece um número significativo de verbos que indicam ação talha/moe/remoe/remorrendo, com direito à gradação verbal e neologismo no último. Há a presença de metáforas sinestésicas, a partir do ver e do tatear. A disposição das palavras, além da imagem da bateia, faz lembrar também a da ampulheta marcando implacavelmente o tempo e o ritmo. Deduz-se daí o tempo que o garimpo toma (pode ser a vida toda) e o tempo agonizante de que o poeta precisa para concluir a sua obra. A estrutura fônica utiliza os sons nasais funcionando como uma espécie de engrenagem sonora que vai (re)moendo/remorrendo o engenho de papel até sentir o brilho do estalo na "brita do sol/ no brilho da vida/ no budum do lençol". É como se amalgamassem exercícios físicos, mecânicos, intelectuais e imagéticos. E um componente erótico surge com a expressão "no budum do lençol". O surgimento do metal precioso poderá propiciar intensos momentos de prazer ao garimpeiro e por que não ao leitor.

O sexto e o sétimo blocos selecionados são exemplos da presença forte do social. Dois verbos intransitivos dão o tom do sexto /ruge/geme. Aparentemente são sinônimos. Na verdade, os dois primeiros versos "a barriga ruge/ geme de gente" fazem parte do imaginário popular, com exceção do inusitado advérbio de modo. Os três adjuntos adverbiais de lugar que se seguem, sempre precedidos da preposição contraída /na/, realizam trocadilhos nominais a partir de variações sonoras como/geme/gente/gema, sede/séde/seda. O acento colocado serve para mostrar a variação do som fechado para aberto assim como provoca uma nova gradação poética. Além disso, pelo menos duas catacreses se apresentam nos versos "geme de gente/ na boca da sede", podendo inclusive os dois últimos serem considerados catacreses sinestésicas, pois é difícil não pensar em pelo menos dois sentidos diferentes (visão e tato), sobretudo no último verso "na seda da gema". Não por acaso gema vem em itálico, pois representa o motivo 
maior da descoberta aurífera. Diz o ditado popular que quem acha diamante, acha ouro. A palavra certa para o poeta pode ser a sua pedra preciosa. Caso ela não apareça, pode ser motivo em pensar em nova vida que seja melhor do que a dele, como em "Morte e Vida Severina", de João Cabral de Melo. O cortejo passa com um lençol ocupado por um corpo, que talvez não tenha gozado da alegria de viver intensamente e começa a refletir tudo o que passou diante dos seus olhos.

No sétimo bloco escolhido, retorna a imagem da bateia. A sua base, sintaticamente falando, é um adjunto adverbial de lugar, posto que seja serviço de "profissional do garimpo". Em seguida, em dois versos, vem a oração principal, "o homem/ oficia a rejeição". Morfologicamente três palavras com a mesma terminação eleição/rejeição/patrão sustentam a sonoridade do poema. Há um apelo ideológico que vai se inflamando na medida em que o poema se aproxima do final. Nos blocos anteriores, tratava-se simplesmente de garimpeiro, aqui a relação homem (empregado) versus patrão (empregador) parece ter chegado a um momento de ruptura. Popularmente, sabe-se que o garimpeiro opta por essa atividade por saber que não mais terá patrão. O que tira é dele, depois de pagar a porcentagem que cabe ao dono da terra. Logicamente terá de produzir, senão de nada valerá essa libertação.

O oitavo bloco selecionado mostra um momento de humor, causado pelo achamento do minério. Não é todo dia que "um conto de réis/ é chama que acende cigarro", somente no dia do achado. O garimpeiro se sente poderoso, torna-se gastador, valente, a ponto de torrar quase tudo que ganhou. Em três versos, novamente em situação de adjunto (desta vez de tempo), o social se antepõe ao lírico. Não há maiores recursos estilísticos neste bloco. Do ponto de vista fonéticofonológico, ele vai rimar achado com cigarro. Vale pela simplicidade humorística quando se diz que fulano está acendendo fogo com nota de um conto de réis.

O penúltimo bloco escolhido mostra uma presença forte de aliterações do /f/ e /t/, em palavras significativas como “o tempo passa 
em pratos" (pode ser o da balança que pesa o mineral), "os prantos (advindos da não recolha de diamantes) feitos/ de fatos/ atos/ faca”. Através de uma alternância sonora o garimpeiro vai consumindo seu tempo com a ilusão de constituir fortuna. O último verso, "diamante de enrola", simboliza bem essa dura realidade utilizando uma expressão regional. Só o poeta poderia mostrar o caminho das pedras. E ele é íngreme. É a questão da esperança do achado da fortuna - que está postergada e daí o sofrimento de quem sabe que isso pode não ocorrer no tempo presente, no aqui e agora, daí o tempo indefinido, que se prolonga... - talvez para uma nova vida, nova geração, onde não haverá fome, porque os pratos estarão cheios do achado. O diamante alimenta esse sonho: o de poder ter e o de dar de comer. O tempo da esperança se faz no passado, no presente e no futuro: "garimpo da infinitude".

O último bloco coincide com o fim do poema. De forma icônica, ele representa uma espinha de peixe. O desenho do peixe tem a ver com o matar a fome e com a destruição do rio que o garimpo "comete". É traumatizante. O garimpeiro, mesmo com uma boa traia - os apetrechos necessários para realizar a tarefa - nem sempre conseguirá o seu bom bocado. Silva Freire encerra o poema, utilizando as expressões: "rio abaixo // rio acima”, que lembra a última expressão de Guimarães Rosa no conto "A terceira margem do rio", do livro Primeiras estórias: "e, eu, rio abaixo, rio a fora, rio a dentro - o rio". Todos os caminhos possíveis o garimpeiro percorre. Nenhum caminho certo leva à fortuna. Como se fosse uma boca de peixe de cada lado, a expressão da outra boca é "garimpo da infinitude". No meio "eixo de peixe". O trocadilho poético sonoro teimosamente se inscreve. Todas as palavras nomeiam a esperança. Nenhum verbo sobrou no fundo da bateia. O poeta sumiu com essa pedra. Até parece que essa categoria gramatical não engasta o verbo. O verso elegeu o nominável e depurou o inominado. A lembrança à recomendação de Mallarmé ao amigo Degas surge naturalmente: "poesia não se faz com idéias, mas com palavras" 5 .

5 Expressão reproduzida por Paul Valéry, no ensaio "Poesia e pensamento abstrato", 
Depois de muitas bateias o poeta se amalgama ao garimpeiro. Todo garimpeiro tem uma esperança. A estória é o que alimenta. E qualquer leitor que se abeire dessa poesia, conheça ele ou não Mato Grosso e os garimpos, será alimentado pela tradição de um Estado que já foi rico e pujante, hoje é pátria desses versos de Silva Freire. Esse poema, que fez da história a leitura de um povo, que fez da dor transida - quando Cuiabá viveu a febre do ouro - a memória de um poeta que não pode ser esquecido. Esse é o valor de Silva Freire. Ele viveu como um garimpeiro de palavras.

\section{Referências bibliográficas}

CAMPOS, Haroldo de; CAMPOS, A.; PIGNATARI, Décio. Teoria da poesia concreta: textos críticos e manifestos 1950-1960. $4^{\text {a }}$ ed. Cotia-SP: Ateliê Editorial, 2006.

CARVALHO, Carlos Gomes de. A poesia em Mato Grosso. Cuiabá: Verdepantanal, 2003.

FREIRE, Silva. Presença na ausência do tempo. Wlademir Dias-Pino (org.) Cuiabá, MT: EDUFMT, 1991. (Trilogia cuiabana, v. 1) . Na moldura da lembrança. Wlademir Dias-Pino (org.) Cuiabá, MT: EDUFMT, 1991. (Trilogia cuiabana, v. 2) 1986. . Freire: catálogo de exposição. Cuiabá: Imprensa Universitária, Águas de visitação. $4^{a}$ ed. Cuiabá: Leila Barros Silva Freire, 2002. Edição póstuma.

"Separata da Revista/Documento" In: Cuiabá/200 anos de carnaval. Prefeitura Municipal de Cuiabá: 1976.

PINO, Wlademir Dias \& CUNHA, Célio da. "Manifesto mosaico cuiabano”. In: Diário de Mato Grosso: Cuiabá. (Suplemento nº 3) p.3, 19 fev. 1977.

GALVÃO, Dácio Tavares de Freitas. Da poesia ao poema: leitura do poemaprocesso. Natal: Zit gráfica e editora, 2004.

LIMA, Marinei Almeida. "Pindorama: um passeio em seu texto editorial". In: RAMOS, Isaac Newton Almeida; RODRIGUES, Agnaldo (Orgs.). Ensaios de Literatura Comparada: Portugal, Brasil, Angola, Cabo Verde. Cáceres, MT: Unemat Editora, 2004.

MAGAlHÃES, Hilda Gomes Dutra. História da literatura de Mato Grosso: século XX. Cuiabá: UNICEN, 2001. (Coleção Tibanaré)

MENDONÇA, Rubens de. História da literatura mato-grossense. $2^{\underline{a}}$ ed. especial. Cáceres: Unemat Editora, 2005.

PINO, Wlademir Dias. Processo: linguagem e comunicação. 2 $2^{\mathrm{a}}$ ed. Petrópolis: Vozes, 1973.

. A separação entre inscrever e escrever (Exposição) Catálogo. Cuiabá: Edições do Meio, 1982.

do livro Variedades. 